\title{
Individual Factors Influencing Acceptability for Environmental Policies: A Review and Research Agenda
}

\author{
Emma Ejelöv * and Andreas Nilsson \\ Department of Psychology, University of Gothenburg, 41314 Gothenburg, Sweden; andreas.nilsson@psy.gu.se \\ * Correspondence: emma.ejelov@psy.gu.se; Tel.: +46-31-786-4674
}

Received: 19 February 2020; Accepted: 18 March 2020; Published: 19 March 2020

check for updates

\begin{abstract}
To facilitate an understanding of why some environmental policies are acceptable to private citizens and why some are not, we review individual factors that influence the acceptability of environmental policy measures. The factors are categorized in demographic factors, such as age and gender, personal factors such as values and ideology, and policy specific beliefs such as perceptions of how fair or effective a policy is. The reviewed studies indicate that demographic factors generally have small effects on acceptability, that ideology seems to be a consistent predictor among personal factors, and that policy specific beliefs may be effective in explaining acceptability but that the relative importance of the specific beliefs may vary between policy contexts. However, we note methodological concerns in the field of environmental policy acceptability that limit the conclusions that can be drawn from reviews or meta-analyses. We end by giving suggestions for how this field can move forward to provide policy makers with more detailed tools on how to design acceptable environmental policies, for example by introducing more experimental designs, and the standardization of targeting factors, as well as acceptability measures and the improved categorizations of policy tools.
\end{abstract}

Keywords: environmental policy; acceptability; individual factors; policy-specific beliefs; review

\section{Introduction}

Environmental problems such as global warming and air pollution pose a serious threat to humanity and the ecosystems. While some of these problems, especially small-scale problems entailing low-cost behaviors, may be alleviated by encouraging private citizens to act, it is evident that policy measures are needed to manage the large-scale problems and behaviors, that require a high degree of sacrifice [1].

The implementation of policies aimed at reaching environmental goals will however present difficulties for politicians, as many of these policies are unpopular among citizens. If general public opposition to accept the measures is too pervasive, politicians are likely to hesitate to implement them. Thus, unless policy measures exhibit acceptability among the general public, they will not likely be supported in the political sphere [2]. However, what are the most important factors in explaining why private citizens have negative or positive attitudes toward these policy measures? This knowledge is needed in order to effectively promote acceptability toward a certain policy measure. Much research has been conducted measuring peoples' attitudes to existing policies (i.e., acceptance), but in order to implement new policies, research has to be able to provide decision makers with an understanding of how and why citizens are likely to respond to these implementations, that is, attitudes prior to implementation. Previous reviews on attitudes toward environmental policy have either focused exclusively on a single environmental domain, like climate or congestion policies [3-5], or focused on a 
specific set of determinants, like political factors [6]. In this narrative review, we aim to describe the effects of a range of individual level factors, such as sociodemographic variables, personal factors and policy-specific beliefs, over a range of environmental policy domains, to serve as a resource for both researchers and policymakers. We will highlight some methodological issues in the research field that limit our ability to draw strong conclusions about the generalizability of research findings, and end by describing a research agenda aimed at ameliorating these limitations.

\section{Method}

To gather material for this review, we entered our search terms into the databases PsychInfo and Google Scholar. To find papers suitable for inclusion in this review, we searched various combinations of the terms "policy", "support", "acceptability", "attitude" and "environment". The search was conducted between October 2017 and December 2017. As a second step in our literature search, we examined the reference lists of the articles gathered from our data base searches to include additional papers that met our inclusion criteria. We included peer-reviewed articles that had specifically researched the effect of individual factors, such as political ideology or values, on attitudes (i.e., acceptability or support), toward policies prior to policy implementation or toward hypothetical policies, with the aim to include key references representative of each policy domain. We excluded articles with dependent variables other than support or acceptability (for example willingness-to-pay, acceptance (attitudes after implementation), or other types of policy perceptions such as belief in climate change) to limit our review more strictly to policy attitudes and thus be more relevant to policy implementation. With this approach, we included a total of 70 original articles. Most of the studies are conducted within psychology and related fields such as political science. In psychological research, the preferred dependent attitude variable has been acceptability, while in political science attitudes toward policy, it is most often operationalized as support for a given policy. The article is divided into two parts; 1) a review of the current literature and research findings, and 2) a research agenda, where we highlight the limitations of the current research and give suggestions for how the field could improve. The review section is further divided into three subsections, beginning with sociodemographic variables, moving on to stable personal factors like values and ideology, and ending by covering variables that are less stable and more situation-specific, called policy-specific beliefs. As the majority of the studies that we found had a correlational methodology, we present the few experimental studies separately below each factor, to highlight the apparent need for additional experimental evidence. In the research agenda, we end by giving suggestions for how this field can move forward in order to provide policy makers with more detailed tools on how to design acceptable environmental policies.

\section{Demographic Factors}

\subsection{Income and Education}

The direct effect of income on transport and environmental taxation acceptability is mostly found to be small to non-existent [7-11], but does vary across studies. Higher income has been found to be indirectly and negatively related to acceptability in the transport domain, via lower intention to reduce car use and perceived infringement on freedom [12], while others have found that both objective and subjective higher income positively predict transport [13,14] and climate [15] policy acceptability. While the effect of income on policy acceptability appears mixed, the effect of education appears more straightforward, as higher education level consistently tends to be related to higher acceptability for climate change [16], transport [10,14,17,18] and recycling policy [19]. However, education and income are measured and reported quite differently across studies. While some measure education and income as interval data (number of years in education and self-reported exact salary), many use different ordinal scales, where education can be measured in anything from eight to two categories. Similarly, income is sometimes categorized in as few as two levels (e.g., low and high income). Studies 
also do not always report the median income in the specific sample, making a comparison between studies difficult.

\subsection{Gender}

Identifying as female has been found to be positively related to acceptability for a range of policy domains, including transport [13,18], energy conservation [20] and recycling policies [19]. However, when people have low trust in government and perceive the policy to be ineffective, identifying as female is related to lower acceptability [21]. Yet, other studies find that men and women support different types of environmental policies, such that men have been found to be more supportive of policies that monitor oil and gas drilling, while women are more supportive of protective environmental policies [22]. It should be noted that the majority of studies we collected had an overrepresentation of men, ranging from $47 \%$ to $73 \%$.

\subsection{Age}

Both in the transport and climate policy domain, some studies find that older age is positively related to acceptability $[10,15,18]$, while others find a negative relationship between age and acceptability $[16,17,23]$ and others yet find no relationship at all [13]. The mixed findings concerning the influence of age on policy acceptability may be due to sample specific variance as highest and lowest age differed quite substantially between studies (mean age ranging from 20.4 to 51.7 years). Furthermore, age is sometimes measured as ordinal data with as few as two age levels, making it difficult to compare effects between studies.

In general, sociodemographic variables tend to show little explanatory power when personal factors or policy-specific beliefs are accounted for $[11,14,17]$. Differential effects of gender, age and income may further be due to different demands for policy [13], in that diverse demographic groups might perform the behavior that the policy aims to change, to a different extent. Thus, the effects of sociodemographic variables, with the exception of education, might be hard to generalize from one policy context to another. A comparison between studies or policy domains is possibly also hindered by the fact that many studies do not provide a comparison of their sample with population data. Those that do provide a comparison with the population often state that their sample is more educated and have higher income than the population. Furthermore, the very diverse ways in which demographics are measured (e.g., income as interval data or as ordinal data with two categories) could yield quite different estimates of what the effect of income on acceptability is. Not all studies measure all of these demographics, and omission of, for example, gender or education in a regression may result in different estimates for other demographic variables. Thus, given the diverse measurements of demographic variables, it is currently difficult to estimate whether differences between studies actually reflect differences between policy domains or instruments.

\section{Personal Factors}

\subsection{Values}

The effect of values on acceptability for environmental policies are often studied in the context of the value-belief-norm theory of environmentalism (VBN [24]), predicting that stable factors like values have an effect on policy acceptability, through more specific beliefs and moral considerations. The VBN theory identifies three different value clusters: egoistic, altruistic and biospheric values. These three clusters can also be organized into two broader value categories often studied in an environmental policy context: the self-enhancement and self-transcendent value clusters [25]. Self-transcendent values primarily make people focus on collective rather than individual outcomes, while the opposite is true for self-enhancement values [26]. These collective outcomes can either be environmental ones (corresponding with biospheric values), or the outcome for people in society (corresponding with more altruistic values), while self-enhancing values in the environmental domain primarily involve 
egoistic (e.g., minimizing financial loss) and hedonic values (e.g., minimizing discomfort). People with self-transcendent or biospheric values tend to generally express greater support for environmental policies, including taxes [7], transport pricing [14,27,28], climate change mitigation [29,30], renewable energy [26,31], and environmental food policies [32]. Biospheric values can be especially important in explaining the acceptability for more coercive policies, like push measures [33]. Conversely, endorsing egoistic or self-enhancing values is associated with lower support for environmental policies and also higher acceptability for a range of policies that are damaging to the environment $[26,27,31,34]$. Thus, policies in line with ones' values may be perceived as more acceptable. Environmental concern has further been shown to mediate the relation between self-transcendent values and support for environmental policies [35], while personal norms have been found to mediate the relation between biospheric values and acceptability of transport and energy policies [36,37]. The other two dimensions of Schwartz, which value circumplex, openness and conservation, have received less attention in the environmental domain. However, individuals who hold traditionalist values (corresponding more with the conservation value cluster) tend to express lower support for climate change policy (cf. research on ideology) [29]. Believing in absolutes has also been shown to be indirectly related to greater acceptability for transportation policies, via a greater trust in government [38]. While values tend to only explain about $4 \%-6 \%$ of the acceptability variance in most studies, there are some exceptions that suggest that values may predict some policy instruments better than others $[33,35]$. The role that values play in environmental policy support may furthermore vary, depending on contextual factors. When looking at the effect of values in the workplace, endorsing environmental values is related to greater acceptability for climate policy for those working in the public but not the private sector, due to a mediating influence of different organizational norms [39].

\section{Experimental Research}

Experimental research on the fit between policy information and values show that when people endorsing biospheric values receive information about the environmental impact of a policy issue (i.e., value-congruent information), acceptability may increase [40]. Similarly, receiving information about anthropocentric aspects of a policy may increase acceptability for people endorsing egoistic values [28]. Presumably, receiving value-congruent information about a policy can affect how the policy is evaluated in terms of policy-specific beliefs.

\subsection{Personal Norm}

Together with values, personal norms for pro-environmental attitudes are often studied in the context of the VBN theory. Personal norms, or feelings of moral obligation, are often positively related to acceptability for a range of policy domains, including transport [41,42], energy [37], and environmental tax policies [7]. Personal norms may, however, be more predictive of acceptability for energy policies [37] than for transport policies [36], possibly as personal norms might be more associated with less costly behaviors, such as acceptability assessments, rather than costly behaviors, like change of transport mode. Other studies have however found that personal norms are especially important for push measures, which often entail more costly behavioral changes [43].

\section{Experimental Research}

When measuring spillover from a framing of energy saving as either a monetary or pro-environmental act, for people endorsing strong personal norms of conserving energy, the environmental framing further increases acceptability compared to the monetary framing [44].

\subsection{Ideology}

Identifying as liberal or democrat is consistently related to higher support for climate [30,45-47], resource conservation [48], and recycling policies [19]. Similarly, classifying oneself politically as more left-wing increases the acceptability of environmental taxes [7,49] and climate policies [16]. Conversely, 
identifying as republican or conservative is consistently negatively related to acceptability, across policy issue and also when controlling for level of trust in government [50]. Political ideology also has an effect on acceptability at a country level, such that people from countries with a right-wing compared to left-wing ideology tend to be less supportive of climate policies [51]. Right-wing oriented people tend to find less compared to more coercive policies (i.e., pull versus push measures) more acceptable [33], possibly because the former is perceived as preserving more individual freedom than the latter. One antecedent of the acceptability difference between right- and left-wing people might be that left-wing individuals typically are more environmentally concerned than right-wing identifiers [7]. Furthermore, the relationship between political ideology and acceptability is weaker when controlling for perceived individual and environmental outcomes [47], indicating that the relation might be mediated by policy-specific beliefs.

\section{Experimental Research}

In a framing study, the ideological difference was reduced when the positive consequences of acting against climate change was made salient, as opposed to the negative consequences of not acting against climate change [46], further indicating that conservatives and right-wing people might respond better to more positive and rewarding policy measures.

\subsection{Trust}

Trust indicates "a psychological state comprising the intention to accept vulnerability based upon positive expectation of the intention or expected behaviour of another" [52] (p. 395), and can be viewed as both a personal predisposition as well as a context-specific belief [26]. We make a distinction between political trust and general trust on the one hand, which are categorized as personal factors, and specific trust on the other hand, which is categorized as a policy specific belief.

\subsection{Political Trust}

Higher trust in government has been found to be indirectly and positively related to acceptability, via policy-specific beliefs such as perceived fairness, infringement on freedom and perceived effectiveness of transport and environmental tax policies [21,38]. Trust in government and politicians also have a direct association with environmental tax acceptability [7,49], and support for government action to address environmental policies [50]. Trust in government may also act as a mediator between values and acceptability [38]. The acceptability of environmental taxes was, however, better explained by institutional trust rather than trust in politicians [33]. Others still found no effect of trust in government, politicians or institutions on climate or transportation policy acceptability $[15,46,53]$. The mixed effect political trust has on acceptability may be dependent on which level a policy is supposed to be implemented at and thus how involved the government is perceived to be. For example, when trust in government is measured on a more general level, the effect is not as pronounced as when it is measured on a more specific level [21].

\subsection{Generalized Trust}

While most studies have focused on the effect of political trust on acceptability, only a few have looked at the influence of generalized trust. The evidence appears mixed, where some studies find no effect of generalized trust $[16,33]$, while others find that it is positively related to support for environmental taxes [7]. These mixed results could however be due to what other trust measures are included in analysis. Which kind of trust is important for policy acceptability might depend on what factors are responsible for decreasing acceptability. If the issue of climate change is perceived as a scientific rather than a political question, trust in science could be more important than trust in politicians, while if there is uncertainty whether the government will use tax revenue honestly, trust in government may be more important. However, if there is some uncertainty about whether the general 
public will comply with environmental taxation as in the aforementioned study, then generalized trust may be important in predicting acceptability.

\section{Policy-Specific Beliefs}

\subsection{Specific Trust}

Trust in the specific authorities responsible for policy implementation is related to lower perceived risk of a policy, which in turn is positively related to acceptability for other nuclear power and water conservations [54,55], especially when knowledge about the environmental hazard is low. However, when studied in relation to renewable energy policies, specific trust is not related to risk evaluation and subsequent acceptability [56], possibly because policies on nuclear power involve a higher degree of uncertainty and thus require a higher level of trust. Specific trust may thus help form evaluations of a policy, such as perceived cost and benefits, when people have little prior knowledge of the policy [26]. In the climate change policy domain, trust in science or environmentalists and distrust in industry (such as coal and oil industries and scientists working for such industries) is further directly and positively related to support $[15,46]$. In this instance, it might be that people who trust that climate change is real (and thus have a higher problem awareness) support mitigating policies more.

\subsection{Freedom}

Perceiving that a policy is constraining individual choice is generally related to the lower acceptability for a wide range of policies, including transport pricing polices [12,21,38,53,57], energy policies [58-61], and environmental taxation [21]. There may, however, be some cultural differences, as infringement on freedom has been shown to be negatively related to acceptability in the UK, but not in Japan [38]. It may be that more individualistic countries are more reactant to perceived threats to ones' individual freedom than more collectivistic countries. The more a policy is perceived to infringe on individual freedom, the less fair it is also perceived as [21,57]; subsequently affecting acceptability [42]. Push measures are generally seen as more restricting of freedom than pull measures, which may help explain why they are less acceptable $[42,62,63]$. Additionally, policies that offer people flexibility (e.g., transport policies with credit-based vs. fixed pricing) are more acceptable, presumably because they increase peoples' freedom to choose [64].

\subsection{Fairness}

Fairness can be categorized into three commonly studied categories: scenario fairness; concerning what the perceived individual outcome of a policy will be, procedural fairness; concerns how a policy is introduced to the public and if the public is involved in the decision-making process and distributional fairness; concerning what the expected distribution of costs and benefits in the society will be. Generally, fairness is positively related to acceptability $[12,43,53,57,65,66]$. In the transport domain, perceived fairness has been found to be one of the most important factors associated with acceptability $[12,21,41,42,63]$, and may have stronger associations with policy support than effectiveness [33]. Procedural fairness is linked to acceptability, both directly [26,67] and indirectly, via, among other, trust in authorities [54], and can explain more variance in acceptability than other more specific beliefs, such as perceived outcome [14]. Similarly, perceiving that the costs and benefits of a policy are unfairly distributed in society is negatively related to acceptability $[68,69]$. Perceived fairness itself is also positively related to the perceived effectiveness of a policy $[57,65]$ and outcomes associated with environmental justice and equality [63]. Conversely, perceptions that a transport pricing policy is fair has been shown to be lower when people already have an intention to reduce their car use, possibly because people value the ability to choose for themselves [12]. 
Experimental Research

In an issue-framing study on climate change mitigation acceptability, both conservatives and liberals were more supportive of policies when messages highlighted equity concerns, as opposed to morality or economic efficiency. The equity frame highlighted the uneven distributional effects of climate change among poor island countries [46]. Thus, stressing the distributional unfairness of the problem could be one way of increasing support for environmental policies.

\subsection{Effectiveness}

The effectiveness of a policy can be evaluated in different ways. Perceiving that a policy is effective in reducing both environmental and collective/individual problems is positively related to acceptability for both transport and energy policies $[11,21,53,59,68]$. Effectiveness has also been proposed as a mediator between problem awareness and acceptability of road pricing [57]. Believing that the policy tool itself (e.g., taxes or subsidies) is effective is also positively related to acceptability [16,23,41]. In the transport domain, pull measures are perceived as more effective than push measures or packages that combine pull and push measures, and are also perceived as more acceptable [43]. However, energy policies that target indirect energy use are perceived as less effective, but not less acceptable, than direct energy measures [59], indicating that a perception of effectiveness might not be a necessary precondition for acceptability in all policy domains. When effectiveness was measured as a perception of the social norm (i.e., effectiveness dependent on people's compliance with the policy), effectiveness was not related to acceptability [42]. However, social norms, when measured as support for policy, predict acceptability for transport policies $[11,12,57,70]$.

\section{Experimental Research}

When people are exposed to a strong (majority support) as opposed to a weak (minority support) social norm message, acceptability for environmental policies increases. Furthermore, when push measures target low-cost behaviors and there is majority support for the policy, push measures can be as acceptable as pull measures [71].

\subsection{Problem Awareness}

Researchers typically distinguish between environmental and collective problem awareness (e.g., car use may increase pollution and/or congestion) [11]. Perceiving that there are both environmental and collective problems tend to be positively related to acceptability in the transport domain [21,23]. Some have found that greater environmental problem awareness is positively related to acceptability, while perceiving collective problems (in this case congestion) is actually related to resistance toward the policy [11], presumably as the people frequently exposed to congestion are the ones who are more dependent on their car for transportation. In the climate policy domain, both individual and collective problem awareness (e.g., effects on individual and collective health) is positively related to acceptability [72]. Perceiving collective problems was, however, positively related to the acceptability for push measures in Japan but not in the UK [38]. In a Swedish context, both environmental and collective problem awareness has been found to be positively related to the acceptability of pull, but not push, policies [42,43]. Problem awareness has also been found to be indirectly related to acceptability, via moral considerations [36,37], and environmental concern [34]. Finally, indirect evidence that problem awareness may affect acceptability comes from research on extreme weather. People with more experience with risky weather show greater support for climate change policies [51], possibly because experience has increased their awareness of the problem. 
Experimental Research

Problem awareness may also be affected by framing, such that when people are told that their in-group is partly responsible for climate change, policy acceptability decreases, because people attribute climate change to natural rather than human causes [73].

\subsection{Perceived Outcomes}

Researchers typically distinguish between perceived individual, collective and environmental outcomes of a policy. When people expect higher personal benefits from a policy, like decreased financial burden or when revenues are allocated to improving individual outcomes, it is positively related to acceptability $[11,18,31,53,60,68,70,74]$. Expecting to be worse off than others is also negatively correlated with acceptability of transport policies [60], indicating that individual outcomes themselves may be evaluated by other types of policy-specific beliefs, such as fairness. That policies that require greater effort on the part of the individual (e.g., push measures) are less acceptable may be indirect evidence that expectations about individual gains and losses is related to acceptability [59]. Similarly, being dependent on cars for transportation is negatively correlated with support for both environmental taxes and transport policies [7,11,75]. Although negative individual outcomes appear to be negatively related to acceptability for a range of policy domains, there is evidence that this may dependent on the specific kind of outcome expected. Perceiving individual outcomes in terms of behavioral, as opposed to financial, costs, has been shown to be positively linked to acceptability of transport pricing policy [76]. There is evidence of environmental concern acting as a buffer against the negative effect of expecting individual costs [77]. However, environmental concern mediates the relationship between values and acceptability more strongly when policies incur non-transparent as opposed to transparent personal costs, indicating that when expecting negative individual outcomes, additional processes may be involved [35]. Further, when considering the simultaneous influence of environmental and collective outcomes, the importance of individual outcomes appear to be less conclusive. Individual outcomes are sometimes not related to acceptability at all and both expected environmental and collective outcomes tend to explain more variance than do consequences for oneself $[32,47,49,60,68,78]$. Environmental outcomes are associated with acceptability, even when people expect negative individual outcomes [14]. Further, expecting policies to have a negative impact on the welfare of the poor is negatively linked to acceptability [68], indicating that collective outcomes may be evaluated in terms of fairness. Individual outcome may thus appear more important for acceptability when environmental and collective outcomes are not included in the analysis. However, which type of outcome expectation best predicts acceptability may also depend on the nature of the policy and what the perceived aim is. The acceptability of a toll charge, for example, was explained more by the expected effects on congestion, while the acceptability of a car-mass-dependent kilometer charge was better explained by perceived environmental outcomes [60].

\section{Research Agenda}

This review has focused on how individual factors, divided into sociodemographic factors, stable personal factors, and policy specific factors, influence environmental policy acceptability over a range of environmental domains, to see which effects seem to generalize. However, there are some methodological and statistical issues in the current literature that make it difficult to draw these types of conclusions. This research agenda will highlight these limitations and offer suggestions on how to improve the field, in order for researchers to draw stronger conclusions about the state of the field and offer more concrete suggestions for policy makers on how to design acceptable environmental policies.

\subsection{Need for Representative Samples}

As indicated in Table 1, while some of the factors have been researched with quite large samples (e.g., research on demographic factors), research on some of the personal and policy-specific factors 
(for example, infringement on freedom and specific trust) have been conducted using considerably smaller samples, that are not representative. To improve the reliability and generalizability of research findings, some of the factors need to be further researched with larger and more representative samples.

Table 1. Summary of the effects of individual factors on policy support.

\begin{tabular}{cccc}
\hline $\begin{array}{c}\text { General Categories of } \\
\text { Individual Factors }\end{array}$ & Factors & Effect on Policy Support & Median Sample \\
Size
\end{tabular}

Note: $(+)$ indicates a positive effect on policy support while $(-)$ indicates a negative effect on policy support.

\subsection{Need for Standardization}

Although many individual factors seem to predict acceptability similarly across policy domains, some of the variables we have investigated (such as the effects of demographics, trust, and perceived outcomes) show quite diverse results, sometimes positively and sometimes negatively predicting acceptability. Whether or not this is reflective of variables having differential effects for different types of policy tools or domains is difficult to ascertain, as most studies measure predictors using different scales or items. To ascertain whether this is the case, it would be useful if measurements of predictors were standardized. Furthermore, the studies reviewed in this paper have measured the outcome variable attitude toward policy, in different ways. We do not yet know the potential difference between expressing liking toward a policy, expressing support and expressing acceptability. Additionally, the majority of the studies measure attitude with a single item, raising questions about the reliability of the individual studies. Hence, a standardization of the attitude variable would be of great value to this field.

\subsection{Need for Research on Causality}

Although much is known about which factors relate to acceptability, far less is known as to which factors are a pre-requisite for policy acceptability and how these factors interact with situational factors in causing acceptability. Previous research in this area has primarily rested on the notion that the policy-specific beliefs explain the overall attitude toward the policy. This conception may be referred to as a rational and at least partly conscious and intentional process. However, an alternative explanation is that when a policy is presented, other more direct processes, such as emotions or heuristics, determine the attitude. These reactions are in turn expressed through more rational beliefs about the policy. There is thus a great need to determine how well these policy-specific beliefs measure the "true" motives behind acceptability, and we urge researchers to employ experimental designs when assessing this. Experimental designs could further facilitate better comparisons between policy 
domains and policy tools, and thus make narrative and systematic reviews as well as meta-analyses more informative. As exemplified by the mixed results of trust and perceived outcomes, it is difficult to gauge the individual contribution of a factor with correlational design, especially as results differ depending on what other factors are controlled for.

\subsection{Need for Research on Emotions}

In relation to the above-mentioned point, if policy-specific beliefs turn out not to cause acceptability, this may open up to the possibility of more direct or heuristic processes. There have been few attempts to investigate the role of emotions in policy acceptability, but the studies indicate that emotions may be important. For instance, emotions like interest, worry and hope have been found to predict climate policy support better than cultural worldviews and sociodemographic variables [30]. Similarly, trust can help form an affective impression of the policy, altering the cost/benefit evaluation, which subsequently affects acceptability [79]. The role of emotions clearly need more attention in future research.

\subsection{Need for Research on Targeting Factors}

A related question is how this research can be used in information or implementation processes. That is, if future research suggest that policy-specific beliefs are not rationalizations but do predict acceptability; what determines these policy-specific beliefs? Is it the policy design, individual factors or an interaction between the two that affects policy-specific beliefs? Future research (see Figure 1 for suggestions for future research) naturally needs to determine how the factors reviewed in this paper influence each other in terms of mediation and moderation, and to use real implementation cases when possible.

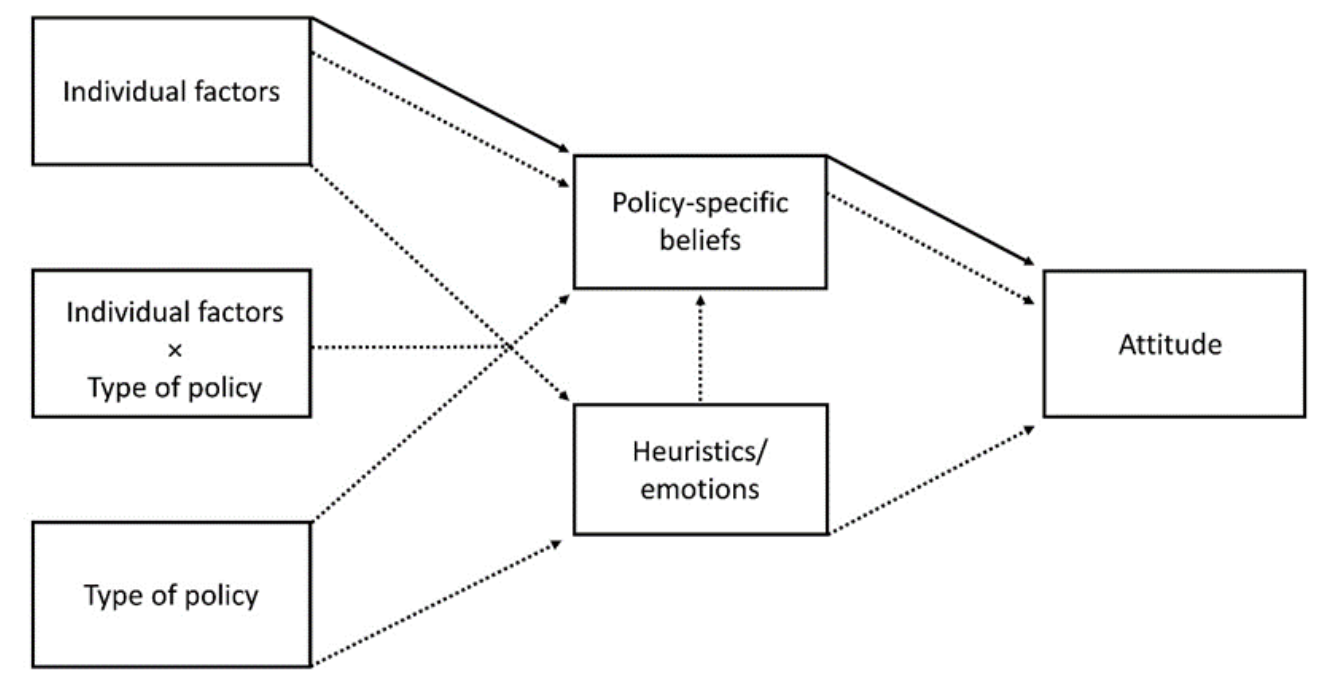

Figure 1. Suggested framework for the continued study of policy acceptability. Solid arrows indicate the existing correlational research. Dotted arrows indicate needed future experimental research, such as how policy design and individual factors, separately and in interaction, causally affect rational and emotional evaluations of a policy as well as acceptability.

\subsection{Need for Improved Categorizations of Policy Tools}

Another potential limitation in this research field is the simplistic categorization of type of policy used. Currently, researchers typically distinguish between pull and push measures. However, this is a theoretical distinction without (to the best of our knowledge) empirical data to support it. Laypeople may evaluate policy tools in other respects, with distinct psychological mechanisms determining support. In a study of pro-environmental behavior attribution, for example, laypeople's perceptions differ from experts', in that laypeople evaluate financial and behavioral costs similarly whereas experts 
do not [80]. Thus, laypeople may not necessarily categorize policies in the same manner as researchers and policymakers do. Clearly, there is a need for an empirical distinction between groups of policies that takes the perceptions of laypeople into account.

\section{Conclusions}

The aim of this paper was to review the individual factors that have typically been studied in relation to environmental policy acceptability and support. Much of the research has focused on stable individual factors such as values and ideology, but also on more situation-specific individual factors, like fairness and effectiveness perception. The demographic factors have generally been seen to have small effects on acceptability. Among the stable factors, ideology seems to be a consistent predictor, while the influence of generalized and political trust is more limited and varied. Values, specifically self-transcendence or biospheric values, show stable positive effects on acceptability, but the association is typically quite weak. When it comes to policy specific beliefs, they are almost always important in explaining acceptability but the relative importance of the specific beliefs seem to vary between policy contexts.

To facilitate better comparisons between studies and policy domains, we make some suggestions for future research. While previous research has largely relied on correlational designs when researching the effects of personal and policy-specific beliefs on attitudes toward environmental policies, we suggest future research implement experimental designs to a larger extent in order to test whether these variables actually cause acceptability. To estimate the generalizability of individual factors on acceptability, these factors should be measured in a standardized way and effects should furthermore be systematically tested across different categories of policies. These categories should ideally be reflective of the types of policies that the general public actually perceive. These recommendations for future research are summarized in Figure 1.

Author Contributions: Both authors have contributed equally to the manuscript. All authors have read and agreed to the published version of the manuscript.

Funding: VR Grant no 2016-03058.

Acknowledgments: We would like to thank Juliane Buecker for her work as research assistant and the three anonymous reviewers for their helpful comments.

Conflicts of Interest: The authors declare no conflict of interest.

\section{References}

1. Mansbridge, J. The role of the state in governing the commons. Environ. Sci. Policy 2014, 36, 8-10. [CrossRef]

2. Glynn, C.J.; Herbst, S.; O'Keefe, G.J.; Shapiro, R.Y. Public opinion and policymaking. In Public Opinion; Westview Press: Boulder, CO, USA, 1999; pp. 299-340.

3. Drews, S.; Van Den Bergh, J. What explains public support for climate policies? A review of empirical and experimental studies. Clim. Policy 2016, 16, 855-876. [CrossRef]

4. Gu, Z.; Liu, Z.; Cheng, Q.; Saberi, M. Congestion pricing practices and public acceptance: A review of evidence. Case Stud. Transp. Policy 2018, 6, 94-101. [CrossRef]

5. Mcgrath, L.; Bernauer, T. How strong is public support for unilateral climate policy and what drives it? Public support for unilateral climate policy. Wiley Interdiscip. Rev. Clim. Change 2017, 8, E484. [CrossRef]

6. Wan, C.; Shen, G.Q.; Choi, S. A review on political factors influencing public support for urban environmental policy. Environ. Sci. Policy 2017, 75, 70-80. [CrossRef]

7. Harring, N.; Jagers, S.C. Should We Trust in Values? Explaining Public Support for Pro-Environmental Taxes. Sustainaibilty 2013, 5, 210-227. [CrossRef]

8. Harrington, W.; Krupnick, A.J.; Alberini, A. Overcoming public aversion to congestion pricing. Transp. Res. Part A Policy Pr. 2001, 35, 87-105. [CrossRef]

9. Odeck, J.; Bråthen, S. On public attitudes toward implementation of toll roads-The case of Oslo toll ring. Transp. Policy 1997, 4, 73-83. [CrossRef] 
10. Rienstra, S.; Rietveld, P.; Verhoef, E.T. The social support for policy measures in passenger transport. Transp. Res. Part D Transp. Environ. 1999, 4, 181-200. [CrossRef]

11. Schade, J.; Schlag, B. Acceptability of urban transport pricing strategies. Transp. Res. Part F Traffic Psychol. Behav. 2003, 6, 45-61. [CrossRef]

12. Jakobsson, C.; Fujii, S.; Gärling, T. Determinants of private car users' acceptance of road pricing. Transp. Policy 2000, 7, 153-158. [CrossRef]

13. Golob, T.F. Joint models of attitudes and behavior in evaluation of the San Diego I-15 congestion pricing project. Transp. Res. Part A Policy Pr. 2001, 35, 495-514. [CrossRef]

14. Nilsson, A.; Schuitema, G.; Bergstad, C.J.; Martinsson, J.; Thorson, M. The road to acceptance: Attitude change before and after the implementation of a congestion tax. J. Environ. Psychol. 2016, 46, 1-9. [CrossRef]

15. Dietz, T.; Dan, A.; Shwom, R. Support for Climate Change Policy: Social Psychological and Social Structural Influences. Rural Sociol. 2007, 72, 185-214. [CrossRef]

16. Hammar, H.; Jagers, S.C. Can trust in politicians explain individuals' support for climate policy? The case of CO2tax. Clim. Policy 2006, 5, 613-625. [CrossRef]

17. Eliasson, J.; Jonsson, L. The unexpected "yes": Explanatory factors behind the positive attitudes to congestion charges in Stockholm. Transp. Policy 2011, 18, 636-647. [CrossRef]

18. Hårsman, B.; Quigley, J.M. Political and public acceptability of congestion pricing: Ideology and self-interest. J. Policy Anal. Manag. 2010, 29, 854-874. [CrossRef]

19. Daneshvary, N.; Daneshvary, R.; Schwer, R.K. Solid-Waste Recycling Behavior and Support for Curbside Textile Recycling. Environ. Behav. 1998, 30, 144-161. [CrossRef]

20. Claxton, J.D.; Ritchie, J.R.B.; Mcdougall, G.H.G. Evaluating Acceptability and Effectiveness of Consumer Energy Conservation Programs. J. Econ. Psychol. 1983, 4, 71-83. [CrossRef]

21. Kim, J.; Schmöcker, J.-D.; Fujii, S.; Noland, R. Attitudes towards road pricing and environmental taxation among US and UK students. Transp. Res. Part A Policy Pr. 2013, 48, 50-62. [CrossRef]

22. Baptiste, A.K. Evaluating Environmental Awareness: A Case Study of the Nariva Swamp, Trinidad; State University of New York: New York, NY, USA, 2008.

23. Mitchell, G. Mapping hazard from urban non-point pollution: A screening model to support sustainable urban drainage planning. J. Environ. Manag. 2005, 74, 1-9. [CrossRef]

24. Stern, P.C. New Environmental Theories: Toward a Coherent Theory of Environmentally Significant Behavior. J. Soc. Issues 2000, 56, 407-424. [CrossRef]

25. Schwartz, S.H. Universals in the Content and Structure of Values: Theoretical Advances and Empirical Tests in 20 Countries. In Advances in Experimental Social Psychology; Academic Press: New York, NY, USA, 1992; Volume 25, pp. 1-65.

26. Perlaviciute, G.; Steg, L. Contextual and psychological factors shaping evaluations and acceptability of energy alternatives: Integrated review and research agenda. Renew. Sustain. Energy Rev. 2014, 35, 361-381. [CrossRef]

27. Milfont, T.L.; Gouveia, V.V. Time perspective and values: An exploratory study of their relations to environmental attitudes. J. Environ. Psychol. 2006, 26. [CrossRef]

28. Nilsson, A.; Hansla, A.; Heiling, J.M.; Bergstad, C.J.; Martinsson, J. Public acceptability towards environmental policy measures: Value-matching appeals. Environ. Sci. Policy 2016, 61, 176-184. [CrossRef]

29. Shwom, R.L.; Bidwell, D.; Dan, A.; Dietz, T. Understanding U.S. public support for domestic climate change policies. Glob. Environ. Change 2010, 20, 472-482. [CrossRef]

30. Smith, N.; Leiserowitz, A. The Role of Emotion in Global Warming Policy Support and Opposition. Risk Anal. 2013, 34, 937-948. [CrossRef]

31. Steg, L.; Perlaviciute, G.; Van Der Werff, E. Understanding the human dimensions of a sustainable energy transition. Front. Psychol. 2015, 6, 1-17. [CrossRef]

32. Worsley, A.; Wang, W.C.; Burton, M. Food concerns and support for environmental food policies and purchasing. Appetite 2015, 91, 48-55. [CrossRef]

33. Harring, N.; Jagers, S.C.; Matti, S. Public Support for Pro-Environmental Policy Measures: Examining the Impact of Personal Values and Ideology. Sustainability 2017, 9, 679. [CrossRef]

34. Shi, J.; Visschers, V.H.M.; Siegrist, M. Public Perception of Climate Change: The Importance of Knowledge and Cultural Worldviews. Risk Anal. 2015, 35, 2183-2201. [CrossRef] 
35. Hansla, A.; Gärling, T.; Biel, A. Attitude toward environmental policy measures related to value orientation. J. Appl. Soc. Psychol. 2013, 43, 582-590. [CrossRef]

36. Jakovcevic, A.; Steg, L. Sustainable transportation in Argentina: Values, beliefs, norms and car use reduction. Transp. Res. Part F Traffic Psychol. Behav. 2013, 20, 70-79. [CrossRef]

37. Steg, L.; Dreijerink, L.; Abrahamse, W. Factors influencing the acceptability of energy policies: A test of VBN theory. J. Environ. Psychol. 2005, 25, 415-425. [CrossRef]

38. Schmöcker, J.-D.; Pettersson, P.; Fujii, S. Comparative Analysis of Proximal and Distal Determinants for the Acceptance of Coercive Charging Policies in the UK and Japan. Int. J. Sustain. Transp. 2012, 6, 156-173. [CrossRef]

39. Nilsson, A.; Von Borgstede, C.; Biel, A. Willingness to accept climate change strategies: The effect of values and norms. J. Environ. Psychol. 2004, 24, 267-277. [CrossRef]

40. Boomsma, C.; Steg, L. The effect of information and values on acceptability of reduced street lighting. J. Environ. Psychol. 2014, 39, 22-31. [CrossRef]

41. Cools, M.; Brijs, K.; Tormans, H.; Moons, E.; Janssens, D.; Wets, G. The socio-cognitive links between road pricing acceptability and changes in travel-behavior. Transp. Res. Part A Policy Pr. 2011, 45, 779-788. [CrossRef]

42. Eriksson, L.; Garvill, J.; Nordlund, A.M. Acceptability of travel demand management measures: The importance of problem awareness, personal norm, freedom, and fairness. J. Environ. Psychol. 2006, 26, 15-26. [CrossRef]

43. Eriksson, L.; Garvill, J.; Nordlund, A.M. Acceptability of single and combined transport policy measures: The importance of environmental and policy specific beliefs. Transp. Res. Part A Policy Pr. 2008, 42, 1117-1128. [CrossRef]

44. Steinhorst, J.; Matthies, E. Monetary or environmental appeals for saving electricity? -Potentials for spillover on low carbon policy acceptability. Energy Policy 2016, 93, 335-344. [CrossRef]

45. O'Connor, R.E.; Bord, R.J.; Yarnal, B.; Wiefek, N. Who Wants to Reduce Greenhouse Gas Emissions? Soc. Sci. Q. 2002, 83, 1-17. [CrossRef]

46. Severson, A.; Coleman, E.A. Moral Frames and Climate Change Policy Attitudes. Soc. Sci. Q. 2015, 96, 1277-1290. [CrossRef]

47. Tobler, C.; Visschers, V.H.; Siegrist, M. Addressing climate change: Determinants of consumers' willingness to act and to support policy measures. J. Environ. Psychol. 2012, 32, 197-207. [CrossRef]

48. Jones, R.E.; Davis, K.L.; Bradford, J. The Value of Trees. Environ. Behav. 2012, 45, 650-676. [CrossRef]

49. Kallbekken, S.; Sælen, H. Public acceptance for environmental taxes: Self-interest, environmental and distributional concerns. Energy Policy 2011, 39, 2966-2973. [CrossRef]

50. Konisky, D.M.; Milyo, J.; Richardson, L. Environmental Policy Attitudes: Issues, Geographical Scale, and Political Trust. Soc. Sci. Q. 2008, 89, 1066-1085. [CrossRef]

51. Alló, M.; Loureiro, M. The role of social norms on preferences towards climate change policies: A meta-analysis. Energy Policy 2014, 73, 563-574. [CrossRef]

52. Rousseau, D.M.; Sitkin, S.B.; Burt, R.S.; Camerer, C. Not So Different After All: A Cross-Discipline View Of Trust. Acad. Manag. Rev. 1998, 23, 393-404. [CrossRef]

53. Jagers, S.C.; Matti, S.; Nilsson, A. How exposure to policy tools transforms the mechanisms behind public acceptability and acceptance-The case of the Gothenburg congestion tax. Int. J. Sustain. Transp. 2016, 11, 109-119. [CrossRef]

54. Ross, V.; Fielding, K.; Louis, W. Social trust, risk perceptions and public acceptance of recycled water: Testing a social-psychological model. J. Environ. Manag. 2014, 137, 61-68. [CrossRef]

55. Whitfield, S.C.; Rosa, E.A.; Dan, A.; Dietz, T. The Future of Nuclear Power: Value Orientations and Risk Perception. Risk Anal. 2009, 29, 425-437. [CrossRef]

56. Bronfman, N.C.; Jiménez, R.B.; Arevalo, P.C.; Cifuentes, L.A. Understanding social acceptance of electricity generation sources. Energy Policy 2012, 46, 246-252. [CrossRef]

57. Bamberg, S.; Rölle, D.; Schade, J.; Schlag, B. Determinants of People's Acceptability of Pricing Measures: Replication and Extension of a Causal Model. Accept. Transp. Pricing Strateg. 2003, 235, 235-248. [CrossRef]

58. Poortinga, W.; Steg, L.; Vlek, C.; Wiersma, G. Household preferences for energy-saving measures: A conjoint analysis. J. Econ. Psychol. 2003, 24, 49-64. [CrossRef]

59. Steg, L.; Dreijerink, L.; Abrahamse, W. Why are Energy Policies Acceptable and Effective? Environ. Behav. 2006, 38, 92-111. [CrossRef] 
60. Schuitema, G.; Steg, L.; Rothengatter, J. The acceptability, personal outcome expectations, and expected effects of transport pricing policies. J. Environ. Psychol. 2010, 30, 587-593. [CrossRef]

61. Leijten, F.R.M.; Bolderdijk, J.W.; Keizer, K.; Gorsira, M.; Van Der Werff, E.; Steg, L. Factors that influence consumers' acceptance of future energy systems: The effects of adjustment type, production level, and price. Energy Effic. 2014, 7, 973-985. [CrossRef]

62. Cherry, T.L.; Kallbekken, S.; Kroll, S. The acceptability of efficiency-enhancing environmental taxes, subsidies and regulation: An experimental investigation. Environ. Sci. Policy 2012, 16, 90-96. [CrossRef]

63. Schuitema, G.; Steg, L.; Van Kruining, M. When Are Transport Pricing Policies Fair and Acceptable? Soc. Justice Res. 2011, 24, 66-84. [CrossRef]

64. Jou, R.-C.; Lam, S.-H.; Wu, P.-H. Acceptance tendencies and commuters' behavior under different road pricing schemes. Transportmetrica 2007, 3, 213-230. [CrossRef]

65. Ittner, H.; Becker, R.; Kals, E.; Schade, J.; Schlag, B. Willingness to Support Traffic Policy Measures: The Role of Justice. In Acceptability of Transport Pricing Strategies; Emerald: Bingley, UK, 2003; pp. 249-265. [CrossRef]

66. Joireman, J.A.; Van Lange, P.; Vugt, M.; Wood, A.; Leest, T.V.; Lambert, C. Structural Solutions to Social Dilemmas: A Field Study on Commuters' Willingness to Fund Improvements in Public Transit1. J. Appl. Soc. Psychol. 2001, 31, 504-526. [CrossRef]

67. Huijts, N.M.A.; Midden, C.J.H.; Meijnders, A.L. Social acceptance of carbon dioxide storage. Energy Policy 2007, 35, 2780-2789. [CrossRef]

68. Kallbekken, S.; García, J.H.; Korneliussen, K. Determinants of public support for transport taxes. Transp. Res. Part A Policy Pr. 2013, 58, 67-78. [CrossRef]

69. Schuitema, G.; Jakobsson Bergstad, C. Acceptability of environmental policies. In Environmental Psychology: An Introduction; Steg, L., De Groot, J., Eds.; Wiley-Blackwell: Oxford, UK, 2012; pp. 175-184.

70. Dieplinger, M.; Fürst, E. The acceptability of road pricing: Evidence from two studies in Vienna and four other European cities. Transp. Policy 2014, 36, 10-18. [CrossRef]

71. De Groot, J.I.M.; Schuitema, G. How to make the unpopular popular? Policy characteristics, social norms and the acceptability of environmental policies. Environ. Sci. Policy 2012, 19, 100-107. [CrossRef]

72. Debono, R.; Vincenti, K.; Calleja, N. Risk communication: Climate change as a human-health threat, a survey of public perceptions in Malta. Eur. J. Public Heal. 2010, 22, 144-149. [CrossRef]

73. Jones-Jang, S.M. Framing responsibility in climate change discourse: Ethnocentric attribution bias, perceived causes, and policy attitudes. J. Environ. Psychol. 2013, 36, 27-36. [CrossRef]

74. Schuitema, G.; Steg, L. The role of revenue use in the acceptability of transport pricing policies. Transp. Res. Part F Traffic Psychol. Behav. 2008, 11, 221-231. [CrossRef]

75. Gaunt, M.; Rye, T.; Allen, S. Public Acceptability of Road User Charging: The Case of Edinburgh and the 2005 Referendum. Transp. Rev. 2007, 27, 85-102. [CrossRef]

76. Schuitema, G.; Steg, L.; Forward, S. Explaining differences in acceptability before and acceptance after the implementation of a congestion charge in Stockholm. Transp. Res. Part A Policy Pr. 2010, 44, 99-109. [CrossRef]

77. Loukopoulos, P.; Jakobsson, C.; Gärling, T.; Schneider, C.M.; Fujii, S. Public attitudes towards policy measures for reducing private car use: Evidence from a study in Sweden. Environ. Sci. Policy 2005, 8, 57-66. [CrossRef]

78. Grisolía, J.M.; López-Del-Pino, F.; Ortuzar, J.D.D. Increasing the acceptability of a congestion charging scheme. Transp. Policy 2015, 39, 37-47. [CrossRef]

79. Montijn-Dorgelo, F.N.H.; Midden, C.J.H. The role of negative associations and trust in risk perception of new hydrogen systems. J. Risk Res. 2008, 11, 659-671. [CrossRef]

80. Truelove, H.B.; Gillis, A.J. Perception of pro-environmental behavior. Glob. Environ. Change 2018, 49, $175-185$. [CrossRef]

(C) 2020 by the authors. Licensee MDPI, Basel, Switzerland. This article is an open access article distributed under the terms and conditions of the Creative Commons Attribution (CC BY) license (http://creativecommons.org/licenses/by/4.0/). 